\title{
Frequência de Parasitos Intestinais em Hortaliças Minimamente Processadas (HMP) Produzidas e Comercializadas no Distrito Federal, Brasil.
}

Iriani Rodrigues Maldonade (III), Vinícios Silveira Mendes (II), Verônica Cortez Ginani (I), Roberta Figueiredo Resende Riquette (I), Eleuza Rodrigues Machado (II,I)

(I) UnB - Universidade de Brasília (Campus Darcy Ribeiro - Asa Norte), (II) ANHANGUERA - Faculdade Anhanguera de Brasília (QI 20 Lotes 1-25 - Taguatinga Norte), (III) EMBRAPA

- Empresa Brasileira de Produtos Agropecuária (Rodovia BR-060, Km 09 (Brasília/ Anápolis), Fazenda Tamanduá Caixa Postal: 218)

\section{Resumo}

Hortaliças minimamente processadas (HMP) podem representar fator de risco para infecções por enteroparasitos. Nesse sentido, o presente trabalho teve como objetivo verificar a ocorrência de enteroparasitos em HMP produzidas e comercializadas no Distrito Federal (DF). Especificamente, foram analisadas amostras de alface (crespa, lisa e roxa), rúcula, couve manteiga, espinafre, ervas frescas (cebolinha, salsinha, coentro e manjericão) e brotos de feijão e alfafa. Para seleção da amostra, foram contatadas as agroindústrias do DF inscritas na Diretoria de Inspeção de Produtos de Origem Vegetal e Animal (DIPOVA), visitada a Central de Abastecimento do DF (CEASA/DF) e quatro grandes estabelecimentos varejistas locais. As agroindústrias que produziam HMP e autorizaram a coleta foram selecionadas. Nos demais locais, observou-se a presença de HMP de marcas distintas das agroindústrias visitadas. Para os ensaios parasitológicos utilizou-se metodologia de sedimentação espontânea e as amostras analisadas foram compostas por cinco unidades amostrais. Dessa forma, foram analisadas 41 amostras (205 unidades amostrais), sendo $58,5 \%$ provenientes da agroindústria e $41,5 \%$ do varejo. Na CEASA/DF apenas estava disponível couve manteiga oriunda de uma agroindústria visitada. Os ensaios revelaram presença de pelo menos um parasita 
patogênico em 100\% das amostras. Dentre os parasitas identificados e/ou suas formas evolutivas 53,6\% eram Entamoeba sp., 41,5\% Nematoda sp., 9,7\% Strongyloides, 9,7\% Entamoeba coli, 4,9\% Entamoeba dispar, 4,9\% Ascaris sp e 4,9\% Ancylostomidae sp. Outros contaminantes observados nas amostras foram fungos sp (80,5\%) e insetos diversos (26,8\%). Os dados obtidos indicam condições sanitárias insatisfatórias resultantes de falhas nos procedimentos de higienização, além de condições de cultivo inadequadas. Elevada frequência de helmintos e maior adesividade aos folhosos podem justificar o fato. Outro aspecto relevante é a qualidade da água e adubo usado no cultivo diretamente relacionados à qualidade do vegetal. Os fatores bióticos que se destacam, nesse sentido, são doenças causadas por agentes etiológicos, como fungos e nematóides. Sendo assim, deve-se avaliar a necessidade de ações educativas e informativas que orientem o produtor para garantir que o consumidor receba um produto com a qualidade esperada.

Palavras-Chave: enteroparasitos, hortaliças minimamente processadas, agroindústria

Agência de Fomento: $\mathrm{CNPq}$ 